\title{
Accords sous tension. La redéfinition du contrat social dans l'album Répression
}

\section{Claude Meyer}

\section{(2) OpenEdition}

1 Journals

Édition électronique

URL : http://journals.openedition.org/edl/2452

DOI : $10.4000 /$ edl. 2452

ISSN : 2296-5084

Éditeur

Université de Lausanne

\section{Édition imprimée}

Date de publication : 15 mars 2020

Pagination : 213-216

ISBN : 978-2-940331-73-4

ISSN : 0014-2026

\section{Référence électronique}

Claude Meyer, «Accords sous tension. La redéfinition du contrat social dans l'album Répression », Études de lettres [En ligne], 312 | 2020, mis en ligne le 24 mars 2020, consulté le 16 septembre 2020. URL : http://journals.openedition.org/edl/2452 ; DOI : https://doi.org/10.4000/edl.2452 


\section{ACCORDS SOUS TENSION. LA REDÉFINITION DU CONTRAT SOCIAL DANS L'ALBUM RÉPRESSION}

En mai 1980, le groupe de hard rock français Trust sort Répression, œuvre pleine de rage, où s'expriment les désenchantements contemporains. C'est du moins la lecture qu'on en fait d'ordinaire. Ce qui, en revanche, se perçoit moins facilement, c'est que cet album, composé sur fond de morosité et de reflux des idéaux, est également porteur d'une proposition collective. Certes Répression enregistre l'avènement individualiste et rejette à la fois les formes instituées de vie sociale, mais son horizon n'est pas (exactement) nihiliste. Ainsi, dans sa trame sonore et visuelle (rappelons qu'à l'ère défunte de la musique matérialisée les disques ne vont pas sans leur pochette), de nombreux jalons sont disséminés qui tracent les contours d'une communauté possible. En reprenant librement les réflexions menées par Nelly Wolf dans Le roman de la démocratie, nous aimerions comprendre comment une ouvre issue de la culture de masse pense le vivre collectif à l'orée des années 80. Comment, dans son imaginaire, se refaçonne le contrat social au moment même où l'individualisme radical prend ses quartiers.

C'est bien sûr Antisocial, le titre-phare de l'album, qui dresse avec véhémence le constat d'une société s'atomisant. Il faut dire que le contexte historique immédiat offre un tremplin jusqu'alors inédit aux idées individualistes. Depuis 1978 en Grande-Bretagne et à partir de novembre 1980 aux États-Unis, des politiques néolibérales sont implémentées tambour battant, respectivement par Margaret Thatcher et Ronald Reagan. Elles impliquent la dissolution ou, à tout le moins, l'affaiblissement des modes traditionnels d'association (on se souvient du laminage du syndicalisme opéré par Thatcher au cours de la décennie) et font la promotion 
de l'individu entrepreneurial. Dans son dispositif énonciatif, Antisocial s'adresse à un individu replié sur lui-même ("Tu masques ton visage en lisant ton journal») et engagé dans un combat digne de Hobbes ( Écraser les gens est devenu ton passe-temps»). Cependant, cet allocutaire, qui a compris à la perfection les transformations du jeu social ("ta conduite est trop parfaite») et a, notamment, intégré ses principes égoïstes ("Tu voudrais dialoguer sans renvoyer la balle»), est pris au piège d'un système déréglé, où la justice est "pleine de vices" et où règne un état de conflit interindividuel permanent («Impossible d'avancer sans ton gilet pare-balles»). N'y a-t-il donc aucune issue à cette société funeste détruisant ceux qui y adhèrent?

Si elle existe, cette solution n'est en tout cas pas à chercher du côté des formes de vie collectives qui ont émergé dans les années 60 et 70 ou dont le modèle a été ravivé alors. Dans la chanson Les sectes, les utopies communautaires à base de spiritualités alternatives sont dénoncées comme des impostures («Hare Krishna, on te manipule», "Jim Jones, vous a fait crever»). Quant au rêve d'une révolution, son dernier avatar en date (la révolution islamiste iranienne à l'origine de l'accession au pouvoir des mollahs) est révoqué dans Monsieur Comédie ("Derrière le vieux croyant/ Se terrait le tortionnaire» - on aura reconnu ici l'allusion à Khomeini). Pourtant, les paroles d'Antisocial ne sont pas complètement exemptes d'une perspective future et d'un lien à créer: "Relève la gueule, je suis là, t'es pas seul» (nous soulignons) est l'invite très explicite faite dans ce sens par l'énonciateur à son destinataire. Notons que la situation d'interlocution sur laquelle est bâtie la prise de parole dans ce morceau relève de l'échange et constitue déjà une forme de sociabilité. Mais alors quelle tournure cette dernière prend-elle exactement?

Divers indices paratextuels s'additionnent pour donner une réponse à cette question. Dans le livret accompagnant le disque, on lit en effet que Répression est dédié à la mémoire de Bon Scott, chanteur d'AC/ DC décédé lors de l'enregistrement et «ami» du groupe. Une autre note remercie ailleurs «l'ami qui nous a soutenu, tout au long de cette aventure». Qu'il s'agisse ou non de la même personne, toujours est-il que l'amitié se dégage comme une valeur qui compte dans l'univers qu'on aurait volontiers cru anomique de Trust. Enfin, au chapitre des crédits encore, le texte du Mitard est attribué à Jacques Mesrine. Là, il n'est plus question d'une relation amicale au sens strict, mais plutôt d'une affinité ou d'un partage fraternel avec quelqu'un dont on adopte les paroles et 
comprend la souffrance (ces paroles, composées en détention, auraient, semble-t-il, été léguées au chanteur du groupe par la fille de Mesrine ellemême). Au fil du paratexte s'égrène donc une liste de semblables avec qui Trust signale qu’il fait ou a fait société.

Cette société de proximité, entre pairs, correspond visiblement aussi au rapport que le groupe désire établir avec son public. Elle structure par exemple l'incontournable présentation des musiciens, qui, dans le cas présent, ne sont désignés ni par leur nom d'état civil, ni par un pseudonyme de star, mais par des diminutifs: Bernie, Nono, Vivi et Jeannot. Familiarité et accessibilité qu'accentue la photo placée au dos de la pochette. Les quatre musiciens y sont éparpillés au milieu de la foule d'un bar ou d'une salle de concert, vraisemblablement à Londres, où a été enregistré l'album. Au centre, le guitariste passe son bras autour des épaules d'une jeune femme au visage fermé. Il semble la consoler. Une fois encore, la valeur de fraternité fait retour.

La mise en scène diffère, par contre, sensiblement lorsqu'on passe à l'image plus léchée du recto. Les membres du groupe sont isolés sur fond noir, chacun étant renvoyé à son reflet déformé. Nulle chaleur collective sur ce cliché, mais plutôt l'exhibition d'individualités clivées. L'effet de diptyque constitué par les deux illustrations principales de l'album révèle alors la teneur complète du projet sociétal contenu dans Répression. Où il s'agit de fédérer non pas tant les exclus ou les marginaux, mais les reclus, les sujets aliénés qui, tout en déclarant leur différence ou leur dissidence, se retrouvent malgré tout pris dans les rets du système. Punk sans avenir (la jeune femme de la photo), rocker australien engagé dans une mortelle fuite en avant (Bon Scott) ou ennemi public mélangeant lutte révolutionnaire et grand banditisme: pour aucun n'existe d'échappatoire. Ėre du vide donc, selon le titre de l'ouvrage de Gilles Lipovetsky publié trois ans plus tard? Pas exactement, car cette communauté, certes en partie négative, fondée sur la haine et le deuil (colère, tristesse, emprisonnement et mort définissent la tonalité de l'album), inclut cependant un volet positif reposant sur les valeurs fortes de la compassion et de la compréhension interhumaine. Dès son nom, remarquons-le, Trust à la fois entérine l'impossibilité de se libérer du système (il fait référence au conglomérat et à l'économie internationale dont le groupe, signé sur CBS, major de l'époque, est un indéniable rouage) et esquisse une solution, toute relative, ancrée sur la confiance et l'honnêteté. 
Ainsi, à l'entame des années 80 , l'alternative communautaire proposée ici n'est ni une énième tentative de sortie de la réalité sociale (forcément naïve et vouée à l'échec) ni un remodelage politique des termes du contrat collectif (les politiciens l'ont bien compris, comme ces municipalités de gauche qui refusèrent d'accueillir la tournée Répression dans leur commune). Ce qui est donc soumis à l'appréciation de chacun, c'est un pacte élémentaire, un rapport d'homme à homme, infra-idéologique et lucide. Rêve de fraternité sans grand lendemain, mais dernier soupçon d'utopie dans Saumur:

Je parle au nom de l'ami qui m'a souri

Dans la vieille ville de Londres

Sincère et sans une ombre.

Claude Meyer

Section de français, Faculté des lettres, Université de Lausanne

\section{BIBLIOGRAPHIE}

Buisson, Jean-Christophe, "Antisocial de Trust», Le Figaro, 23 août 2011, en ligne <https://www.lefigaro.fr/musique/2011/08/24/0300620110824ARTFIG00370--antisocial-de-trust.php>.

Lipovetsкy, Gilles, L'ère du vide. Essais sur l'individualisme contemporain, Paris, Gallimard, 1983.

Wolf, Nelly, Le roman de la démocratie, Saint-Denis, Presses Universitaires de Vincennes, 2003. 